2008-3

\title{
Promoting Self-confidence in Clinical Nursing Students
}

Karen M. Lundberg

Brigham Young University - Provo, karen-lundberg@byu.edu

Follow this and additional works at: https://scholarsarchive.byu.edu/facpub

Part of the Other Nursing Commons

\section{Original Publication Citation}

Lundberg, K. (2008). Promoting self-confidence in clinical nursing students. Nurse Educator, 22, 86-89.

\section{BYU ScholarsArchive Citation}

Lundberg, Karen M., "Promoting Self-confidence in Clinical Nursing Students" (2008). Faculty Publications. 5223.

https://scholarsarchive.byu.edu/facpub/5223

This Peer-Reviewed Article is brought to you for free and open access by BYU ScholarsArchive. It has been accepted for inclusion in Faculty Publications by an authorized administrator of BYU ScholarsArchive. For more information, please contact ellen_amatangelo@byu.edu. 


\section{Promoting Self-confidence in Clinical Nursing Students}

\author{
Karen M. Lundberg, MS, RN
}

${ }_{0}$ Clinical nursing instructors are continually telling their students that they just 厗need more confidence. But how do students find this needed confidence and how 그으. 产O confidence in relationship to teaching behaviors and strategies for increasing 产self-confidence, such as simulations, peer modeling, story telling, skill review 产 Sessions, and journaling.

$\sum_{3}^{\infty}$

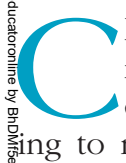
linical nursing education demands that students move quickly from theoretical learn의의 to real-life situations dealing with 商illness and patients. For some students, this transition can be both frightening 言and filled with self-doubt. ${ }^{1}$ Lack of self产Confidence in student nurses can intertere with their ability to acquire new 缡knowledge and hinder their ability to 畩tackle difficult situations. Both capable 鿷and incapable students can experience lack of confidence because individuals 毵are typically guided by their beliefs and 邹perceptions rather than reality. ${ }^{2}$ Con耪scientious clinical nursing instructors onneed to be aware of this phenomenon 就and act promptly to promote an attitude స్ㅐㅇㅢ confidence to reverse a student's neg产ative mindset. Instilling confidence in osstudent nurses early provides a foundagुtion for the acquisition of knowledge 莃and the successful implementation of 部newly acquired skills.

Belief in one's capabilities to suc"ceed provides the "foundation for human 옹motivation, well-being and personal :aaccomplishment."2(p4) Self-confidence is an important attribute in nursing students. Students who possess self-

Author Affiliation: Assistant Teaching Professor, College of Nursing, Brigham Young University, Provo, Utah.

Correspondence: College of Nursing, Brigham Young University, 533 SWKT, Provo, UT 84602 (Karen-Lundberg@byu.edu). confidence believe that they can preserve and ultimately succeed in their clinical goals, whereas students lacking in self-confidence often envision defeat before it happens. Confident students will engage in challenging goals, whereas their less confident peers will avoid the same tasks. Confident students will also approach difficult skills with lower anxiety, ${ }^{2}$ perceive that particular skill as important, and possess a firmer commitment to use their clinical skills. ${ }^{3}$

Clinical confidence cannot be learned in the classroom, rather clinical confidence is acquired in the clinical setting by mastering newly learned skills and experiencing success. Therefore, it is the responsibility of clinical educators to foster confidence in their students through building a confidencerich learning environment. ${ }^{4}$ Educators must be able to recognize underconfidence in their individual students and plan appropriate teaching strategies that will nurture self-confidence.

\section{Literature Search}

CINAHL, PubMed, ERIC, and PsycoINFO databases were used to identify evidenced-based research concerning student confidence and clinical teaching strategies. Keywords included student confidence, confidence, self-efficacy, student self-efficacy, teaching strategies, and teaching behaviors. Search dates were unlimited because of the small amount of literature published concerning clinical confidence and to allow for the inclusion of classical theory. All articles were reviewed individually using criteria such as value added to the understanding of confidence, clinical teaching strategies, and quality of research on student confidence. Sources are primary, with the exception of a few secondary sources included because of their written commentary on theoretical concepts.

\section{Theoretical Framework}

The interconnections between the constructs of confidence, motivation, and success are best described within the theoretical framework of Bandura's Social Cognitive Theory. Central to Bandura's view of human adoption and change is the idea of self-efficacy beliefs. ${ }^{2}$ Bandura described self-efficacy as the "belief one has in being able to execute a specific task successfully." ${ }^{(p 174)}$ I use the term self-confidence instead of selfefficacy because it is more familiar to most educators. Self-confidence influences virtually every aspect of an individual's life, from the individual's ability to think optimistically, persevere through difficulties, and ultimately, complete activities. $^{2}$

Self-confidence provides motivation, which is a key determinant of persisting through difficult learning activities. ${ }^{6}$ For some students, learning new skills is hard work requiring many hours dedicated to the process. Selfconfidence perpetuates the drive or motivation needed to invest in the learning process. Unless students believe that they can be successful, they will not attempt the task in the first place. Students who perceive their effort to be in vain will be frustrated and put forth a decreased effort. ${ }^{6}$

According to Bandura, the most effective way to develop self-confidence is through mastery or perceived successful experiences. ${ }^{2}$ Repeated successes provide individuals with a firm foundation to judge their future attempts. 
Students who interpreted outcomes as successful increased their self-confidence, whereas those who saw failures decreased their confidence. ${ }^{2}$ Modeling or observing others perform a task is less effective than experiencing success firsthand. However, learning vicariously is helpful for individuals who have had little previous experience with the task and can relate to similar attributes in the model. ${ }^{1}$

In addition to an individual's accomplishments and vicarious experiences, Bandura also claims that verbal persuasions and physiological states influence a student's confidence information. ${ }^{5}$ Clinical instructors who are mindful of Bandura's theoretical constructs can develop and implement teaching principles that provide opportunities for repeated successes and observation of confident peers and offer ample encouragement-all within a nurturing, stress-free environment.

\section{Recognizing Lack of Confidence}

Because nursing students are not equipped with signs announcing their clinical confidence, instructors are left with the difficult task of identifying who is lacking in confidence. Clinical nursing instructors first need to discern between students who are lacking clinical confidence versus students lacking in clinical knowledge. No amount of confidence can compensate for incompetence. Careful consideration of personality traits must be used when deciding if a student is underconfident or shy and timid. Student behaviors that might indicate a lack of confidence can be displayed in a variety of actions, such as continually deferring skills opportunities to other students or failing to engage in the clinical setting. Careful assessment of students with poor clinical grades is necessary to determine if low selfconfidence is the cause of their poor performance. Excessive reliance on external resources when not needed is also a symptom of underconfidence. ${ }^{7}$

Recognizing underconfidence can often be a difficult task for nursing instructors because of the different nuances of human behavior. Clark et $\mathrm{al}^{3}$ recommend using an assessment tool to measure students' beliefs about selfconfidence, which allows the faculty to identify gaps in confidence. Early assessment of clinical confidence allows time to tailor the clinical experience to better fit students' needs. Because lack of confidence is often specific to a particular task, ${ }^{2}$ recognizing and identifying the specific gaps of confidence are key aspects to formulating a teaching strategy that appropriately addresses the situation.

\section{Confidence-Building Teaching Behaviors}

Nursing educators mindful of the importance of nurturing confidence in their students will conscientiously control their own teaching behaviors to include techniques aimed at supporting each student's emerging confidence. Confidence-building teaching behaviors are consistent with Bandura's ${ }^{8}$ theory that individuals' motivations and actions are guided more by their belief in their capabilities than what is objectively true. Teaching behaviors of clinical nursing instructors can enhance student confidence through the development of an emotionally safe environment, by being respectful and offering frequent encouragement.

Confidence-building encouragement from faculty links new challenges to recent successes, ${ }^{9}$ thus reminding students of their past accomplishments. A student's ability to retain that feeling of success can be short lived ${ }^{2}$; therefore, frequent reminders of past performances might be necessary. Encouragement must be timely to connect the recent experience with a positive feeling, thus helping to reinforce the effort and encourage persistence. ${ }^{9}$ Providing frequent, immediate, and taskspecific feedback with corrective comments and justified praise are essential confidence-building teaching behaviors.

Faculty can encourage confidence in their students by orchestrating successful events early on in their clinical experience. Hoy ${ }^{10(\mathrm{p} 2)}$ explains, "efficacy judgments are most malleable in the early stages of mastering a skill and become more set with experiences." This principle explains the importance of perceived success on the ability of students to perform at a later stage of their clinical education. Implications for clinical teaching using this principle include not allowing unprepared students to attempt skills prematurely, thus setting them up for frustration and failure. Instead, underconfident students need to be adequately prepared with the prerequisite knowledge needed and placed in situations where they are most likely to succeed early on.

Instructors can promote confidence through the art of asking encouraging questions and guiding the students through the learning process instead of measuring what they do not know. Nursing students are already proficient self-doubters, and clinical instructors need not reinforce this mindset. Encouraging questions from instructors ask students about their concerns for the patient. Addressing the concerns of student nurses and exploring how to find answers to their concerns promote an emotionally positive learning environment $^{11}$ and allow students to build on their current understanding. Instructors can also respond positively to student answers with "Yes, and..." instead of "No, but..." This response acknowledges the student's effort to answer correctly and sends the clue that there is more needed to answer completely.

\section{Confidence-Buildling Teaching Strategies}

\section{Simulations}

Simulations can range from static manikins to role-playing scenarios and complex high-fidelity human simulators. Clinical simulations of real-life patient situations can help students apply classroom theory to a controlled clinical learning environment. Confidencebuilding principles used by simulation strategies within nursing education include immediate feedback, peer modeling, and opportunities to practice newly acquired skills.

\section{Human Patient Simulators}

Human patient simulators (HPSs) are life-size mannequins equipped with a sophisticated computer capable of replicating human physiology in real time. Through this interface of technology and interactive learning, nursing students can increase their clinical skills, knowledge, and critical-thinking abilities. ${ }^{12}$ Simulation sessions usually involve a small number of students and a faculty member who acts as a facilitator. 
Students are provided the opportunity to implement various nursing interventions and skills, with immediate feedback from both the facilitator and the computer in a safe and supportive environment.

Recent research studies reveal that student self-confidence increases after HPS sessions. ${ }^{12-16}$ Surveyed students reported increased confidence in specific clinical skills such as medication administration and physical assessment skills. ${ }^{12}$ Clinical nursing concepts such as collaborative teamwork and critical thinking skills were also increased after HPS sessions. ${ }^{16}$ However, not all confidence built in the simulation laboratory is transferred to the actual clinical setting. ${ }^{14}$ For this reason, instructors cannot assume that students who are confident in the simulation laboratory would automatically be confident in the real-life clinical arena.

\section{Role Playing}

Role playing is a type of simulation technique in which the students portray various roles for the purpose of experiencing that role in "specified life like problem situations."17(p11) Other students might engage in the activity through observing and analyzing the observed behaviors. ${ }^{18}$ Role playing has been widely used in nursing education for the purposes of demonstrating and practicing communication skills relating to patient interactions and professionalism. Christiaens et $\mathrm{al}^{19}$ explain that role playing can easily be adapted to the clinical setting because of the flexibility of the technique. Role playing in postclinical conferences allows students to explore situations just recently encountered during their clinical experience. Other examples of role playing within the clinical setting include simulating a "change-of-shift" report, telephone situations, ${ }^{20}$ and dealing with difficult patients.

Role playing is inherently less predictable because of the nature of activity. A student's interpretation of the assigned role may differ from person to person. Faculty using role playing for the purpose of building confidence must be mindful of the inability to guarantee positive outcomes. Repeated failures or feelings of self-doubt after a poor role-playing experience could diminish instead of build confidence.

\section{Peer Modeling}

Peer modeling is the purposeful matching of students to observe a desired behavior (as opposed to a skill as in peer learning) performed by their peers. ${ }^{21}$ Clinical assignments are then made with the intent of pairing a clinically confident student with a less confident student. Peer models may be particularly effective because the model and the observer share the common trait of being students. ${ }^{22}$ Perceived similar attributes among peers relate the message to underconfident students that "if he or she can do it, then I can do it also." Morgolis and MacCabe 9 do caution that instructors should carefully select models that are respected by their peers. Other teaching strategies using the concept of peer modeling include simulation ${ }^{19}$ and stories. During these teaching sessions, students are able to witness selfconfidence in their peers and build their own confidence through the vicarious experience of others. ${ }^{2}$

\section{Sharing Stories}

Students should be given frequent opportunities to share their stories with their peers and more experienced nurses. ${ }^{11}$ Relating clinical experiences to others helps students develop realistic expectations of their clinical skills and allows for immediate feedback from others, thus reinforcing their perceived abilities to function as a nurse. Sharing stories is also another from of peer modeling where other students can witness how their peers work through difficult situations.

Postclinical conferences can offer the ideal situation for sharing stories. Instructors might ask students who have displayed confidence to share how they solved a particular clinical problem. Handpicking successful students might allow for some control over the situation, thus preventing excessive failure or negative stories from being shared. Debriefing comments from the instructor can include highlights of positive behavior and appropriate praise.

\section{Skill Reviews}

Formal skill review sessions might replace a clinical day, with students rotating through various skill stations manned by facilitators dedicated to providing opportunities for the review and practice of clinical skills. Such review sessions might be particularly helpful if gaps of time have occurred between the previous and current clinical experience. Students who have completed a skill review report a boost in confidence levels. ${ }^{23,24}$ Informal reviews or "closet rehearsals" are impromptu review sessions conducted just before performing the clinical task.

Nurse educators using such skill review must allow ample time for students to practice until they have experienced success. Closing the review session before underconfident students have had time to be successful will only cement the negative mindset of self-doubt. This is especially true of closet rehearsals completed before entering the patient's room, for an unsuccessful attempt at a skill just before implementation can be devastating to an underconfident student.

\section{Journaling}

Clinical journaling provides the students with the opportunity to reflect on their clinical performance through the process of writing. ${ }^{1}$ Journals written with the intent of exploring the students' feelings about their clinical experience rather than reporting the day's activities can provide instructors with both a tool to assess student confidence and a means to offer positive feedback. Clinical instructors responding to student's comments on confidence can focus on successful outcomes and write encouraging responses. Students with low self-confidence might be assigned to keep a clinical log reflecting what they "did right." ${ }^{25}$ Such a log allows students to track their successes, thus enabling them to monitor their previous accomplishments.

\section{Recommendations}

Early assessment of clinical confidence through the use of a confidence assessment tool is recommended. Recognizing and qualifying student's gaps of confidence allow nursing instructors to develop programs and teaching plans that include confidence-building strategies. Evidence suggests that teaching strategies that allow for the practice of 
skills are effective confidence-building techniques. Therefore, teaching plans should include activities such as simulations and skill review. Use of peer modeling, story telling, and journaling has not been evaluated for the purpose of confidence building within nursing education. However, these techniques have characteristics that are consistent with Bandura's theory and should be considered for implementation. Future studies that focus on understanding theories of clinical confidence acquisition and clinical confidence-building teaching techniques are recommended.

\section{RefERENCES}

1. O'Connor AB. Clinical Instruction and Evaluation. Sudbury, MA: Jones \& Bartlett; 2006.

2. Pajares F. Overview of social cognitive theory and of self-efficacy. http://www. des.emory.edu/mfp/eff.html. Accessed August 26, 2007.

3. Clark MC, Owen SV, Tholcken MA. Measuring student perceptions of clinical competence. J Nurs Educ. 2004;42(12):548-554.

4. Flagler S, Loper-Powers S, Spitzer A. Clinical teaching is more than evaluation alone! J Nurs Educ. 1988;27(8):342-348.

5. The National Academy of Sciences. Learning, remembering, believing: enhancing human performance. http://www.nap. edu/catalog.php?record_id=2303. Accessed August 26, 2007.

6. Klein HJ. Motivation to learn and course outcomes: the impact of delivery mode, learning goal orientation, and perceived barriers and enablers. Pers Psychol. 2006;59(3):665-702.

7. Friedman C, Gatti G, Elstein A, Franz T, Murphy G, Wolf F. Are clinicians correct when they believe they are correct? Implications for medical decision support. Medinfo. 2001;10(pt 1):454-458.

8. Bandura A. Self-efficacy: toward a unifying theory of behavioral change. Psychol Rev. 1977;84:191-215.

9. Morgolis H, McCabe P. Self-efficacy: a key to improving the motivation of struggling learners. Clearing House. 2004; 77(6):241-249.

10. Hoy AW. Self-efficacy in college teaching. http://gozips.uakron.edu/ mcgurk/ number7.htm. Accessed August 26, 2007.

11. Haffer AG, Raingruber BJ. Discovering confidence in clinical reasoning and critical thinking development in baccalaureate nursing students. J Nurs Educ. 1998;37(2):61-70.

12. Bremner MN, Aduddell K, Bennett DN, VanGeest JB. The use of human patient simulators. Nurse Educ. 2006;31(4):170-174.

13. Bearnson CS, Wiker KM. Human patient simulators: a new face in baccalaureate nursing education at Brigham Young University. J Nurs Educ. 2005;44(9):421-425.

14. Feingold CE, Calaluce M, Kallen MA. Computerized patient model and simulated clinical experiences: evaluation with baccalaureate nursing students. J Nurs Educ. 2004;43(4):156-163.

15. Gordon JA. The human patient simulator: acceptance and efficacy as a teaching tool for students. Acad Med. 2000; 75(5):522.
16. Schoening AM, Sittner BJ, Todd MJ. Simulated clinical experience: nursing students' perceptions and the educators role. Nurse Educ. 2006;31(6):253-258.

17. Jenkins P, Turick-Gibson T. An exercise in critical thinking using role-playing. Nurse Educ. 1999;24(6):11-14.

18. Gaberson KB, Oermann MH. Clinical Teaching Strategies on Nursing. New York, NY: Springer Publishing Company; 1999.

19. Christiaens G, Baldwin JH. Use of dyadic role-playing to increase student participation. Nurse Educ. 2002;27(6): 251-254.

20. Johnson JH, Zerwic JJ, Theis SL. Clinical simulation laboratory: an adjunct to clinical teaching. Nurse Educ. 1999; 24(5):37-41.

21. Schunk D. Peer models and children's behavioral change. Rev Educ Res. 1987; 57:149-174.

22. Adams K. Modeling success: enhancing international postgraduate research students' self-efficacy for research seminar presentations. High Educ Res Dev. 2004; 23(2):115-129.

23. Mayne W, Jootun D, Young B, Marland G, Harris M, Lyttle CP. Enabling students to develop confidence in basic clinical skills. Nurs Times. 2004;100(24):36-39.

24. Tucker K, Wakefield A, Boggis C, Lawson M, Roberts T, Gooch J. Learning together: clinical skills teaching for medical and nursing students. Med Educ. 2003;37(7):630-637.

25. Baker C. Reflective learning a teaching strategy for critical thinking. J Nurs Educ. 1996;35(1):19-32. 